\title{
HÁBITOS VOCAIS EM DOIS GRUPOS DE IDOSOS
}

\section{Vocal habits in two groups of aged}

\author{
Elisângela Barros Soares ${ }^{(1)}$, Dafne Torres Borba ${ }^{(2)}$, Thalita Karina Barbosa ${ }^{(3)}$, \\ Daniela Malta Medved ${ }^{(4)}$, Ana Cristina de Albuquerque Montenegro ${ }^{(5)}$
}

\begin{abstract}
RESUMO
Objetivo: comparar as diferenças quanto à presença dos hábitos inadequados, as formas de prevenção e os sintomas vocais, mais freqüentes, em dois grupos da terceira idade. Métodos: foi aplicado um questionário com questões do tipo fechada, previamente elaboradas em 45 idosos de ambos os sexos, sendo que apenas um grupo recebeu orientações vocais durante o ano anterior à pesquisa por um profissional fonoaudiólogo. É um estudo descritivo, observacional, transversal. Resultados: de acordo com os resultados, o grupo 2 que recebeu orientação vocal, possui menor freqüência de hábitos inadequados quando comparado ao grupo 1. Quanto às formas de prevenção de distúrbios da voz, a maioria do grupo 1, não possui nenhum cuidado. No grupo 2, já se constata, entre outras formas de prevenção, a referência de realização de treinamento vocal. Com relação à presença de sintomas, o grupo 1 apresentou maior freqüência quanto a cansaço ao falar $(50 \%)$, dor na garganta $(50 \%)$, sensação de corpo estranho (67\%), do que o grupo 2. Conclusão: observa-se que houve diferenças quanto hábitos inadequados, formas de prevenção e sintomas nos dois grupos, sendo que o grupo 2 (que recebeu orientação quanto aos cuidados com a voz) possui índices menores quanto aos hábitos inadequados e sintomas vocais, ou seja, de acordo com os resultados, orientações sobre saúde vocal em grupos de terceira idade é eficaz.
\end{abstract}

DESCRITORES: Idoso; Voz; Saúde do Idoso; Fonoaudiologia; Hábitos

\section{INTRODUÇÃO}

Nos dias atuais tem-se investido cada vez na qualidade de vida, seja qual for a idade e constata-se que o número de idosos, no Brasil, tem aumentado estando na média de 15 milhões e cada vez mais cresce também a busca de um apoio em grupos que são chamados de terceira idade ${ }^{1}$. Esses grupos têm con-

(1) Fonoaudióloga do Memorial Hospital em Goiana; Mestrada em Patologia Geral da Universidade Federal de Pernambuco.

(2) Graduanda do curso de Fonoaudiologia da Universidade Federal de Pernambuco.

(3) Graduanda do curso de Fonoaudiologia da Universidade Federal de Pernambuco.

(4) Fonoaudióloga Professora colaboradora do Curso de Fonoaudiologia da Universidade Federal de Pernambuco; Fonoaudióloga do HGeR/Hospital Militar do Recife; Mestranda em Ciências da Linguagem pela Universidade Católica de Pernambuco.

(5) Fonoaudióloga Professora colaboradora do Curso de Fonoaudiologia da Universidade Federal de Pernambuco; Fonoaudióloga do Serviço de Assistência Social dos Servidores da Polícia Civil do Estado de Pernambuco; Mestre em Ciências da Linguagem pela Universidade Católica de Pernambuco; Doutoranda em Lingüística na Universidade Federal de Pernambuco. tribuído para ajudá-los em vários tipos de assistências, sendo algumas nas áreas: jurídica, de saúde e social. Na área da saúde podemos observar vários profissionais atuando para beneficiar esses idosos, tais como: geriatras, nutricionistas, fisioterapeutas, fonoaudiólogos, entre outros ${ }^{2}$.

Com o envelhecimento, ocorrem mudanças em todo o organismo. O mesmo acontece nas pregas vocais e em outras estruturas que estão relacionadas com a produção da voz. Essa mudança é conseqüência do envelhecimento natural da voz, chamado de presbifonia. Ocorrem, por exemplo, dentre outras mudanças, as variações de freqüência das vozes, na qual as mulheres apresentam tendência para uma voz mais grave e os homens para mais aguda, pois a espessura de toda mucosa vocal tende a aumentar após os 70 anos, nas mulheres e diminuir, nos homens ${ }^{3,4}$. Verifica-se que é nas regiões brasileiras Sul e Sudeste onde mais se investiga sobre saúde na terceira idade ${ }^{5}$.

Na voz do indivíduo na terceira idade existem duas principais alterações que ocorrem na morfologia da estrutura laríngea: calcificação e ossificação gradual das cartilagens laríngeas ${ }^{6}$. Com isso, ocorre a dimi- 
nuição da mobilidade e a atrofia muscular, nos músculos da laringe, apresentando a presbifonia ${ }^{6}$. Cabe salientar que o processo de ossificação da cartilagens é em geral, tardio e menos extensivo ${ }^{7}$.

O início da presbifonia, seu desenvolvimento e grau de deteriorização dependem de cada indivíduo, de saúde física e psicológica e de uma história de vida, além de fatores constitucionais, raciais, hereditários, alimentares, sociais e ambientais ${ }^{6}$. Alguns aspectos da presbifonia são: redução da capacidade respiratória, aumento da freqüência fundamental nos homens e redução nas mulheres, extensão de freqüências reduzidas em ambos os sexos e perfil de extensão com valores médios ${ }^{6}$.

Independentemente da idade, deve-se ter consciência de manter alguns hábitos saudáveis e evitar alguns hábitos deletérios para promover uma boa saúde vocal, a qual é constituída de formas de prevenção, em que o indivíduo deve ser informado sobre hábitos que podem afetar a qualidade vocal e que precisam ser divulgados ${ }^{8}$. Dentre eles, os mais prejudiciais são: o tabagismo, álcool e hábitos como tossir e pigarrear, já que aumentam o atrito das pregas vocais ${ }^{8}$.

O tabagismo e uso de drogas tais como a maconha, levam a um aquecimento das pregas vocais $e$ podem resultar numa voz mais grave, bem como a morbidade na estrutura laríngea ${ }^{8}$.

Outra informação preventiva é sobre o efeito de Lombard, como a elevação da voz, ou seja, da sua intensidade, devido ao ruído mascarante em lugares que, por exemplo, apresentam competição sonora ${ }^{6}$.

A ingestão de água também deve ser enfatizada para a manutenção da voz. O ideal é 4 a 6 copos de água antes do uso intenso da voz, protegendo contra 0 atrito das pregas vocais durante a fonação ${ }^{9}$.

Existe uma lista de medidas que devem ser tomadas, dentre elas, uma alimentação saudável e regular, evitando alimentos condimentados, choques térmicos por meio de alimentos ou líquidos e evitar falar muito em casos de gripes e alergias ${ }^{9}$.

O uso de sprays e pastilhas é algo que também deve ser orientado, uma vez que estes podem mascarar ou anestesiar as pregas vocais fazendo com que o indivíduo venha a cometer abusos sem percebê-los ${ }^{8}$.

A orientação para uma boa saúde vocal é uma forma de prevenir as disfonias, que são as alterações causadas muitas vezes por um mau uso ou abuso vocal. Cabe ao Fonoaudiólogo a responsabilidade de orientar quanto a cuidados com a voz, evitando com isso maiores transtornos para voz, além da presbifonia.

Sendo assim, o presente trabalho visa comparar as diferenças quanto à presença dos hábitos inadequados, as formas de prevenção e os sintomas vocais, mais freqüentes, de dois grupos da terceira ida- de, em que apenas um grupo recebeu orientações vocais. Com isso, busca-se mostrar a importância de promover, a esses idosos, orientações a respeito das alterações causadas pela presbifonia, evidenciando as melhores formas de prevenção contra o envelhecimento precoce ou o desgaste maior dessa voz.

\section{MÉTODOS}

A pesquisa é um estudo do tipo descritivo, observacional, transversal, sendo desenvolvida com dois grupos de idosos.

Participaram deste estudo, 45 pesquisados, de ambos os sexos, pertencentes aos dois grupos de terceira idade, sendo que um grupo, o qual se reúne semanalmente, freqüentador da Primeira Igreja Batista do Recife (PIBR) (grupo que não recebeu orientação de higiene vocal) é nomeado grupo 1, e o outro, composto por idosos que fazem parte do grupo de terceira idade do Serviço de Assistência Social dos Servidores da Polícia Civil do Estado de Pernambuco (SASSEP), que também se reúnem semanalmente e receberam orientações sobre higiene vocal no semestre anterior a essa pesquisa foi denominado grupo 2 .

O critério de inclusão foi que apenas os indivíduos pertencentes aos grupos da terceira idade deveriam participar da pesquisa. Além disso, os sujeitos do grupo 1 (PIBR) não deveriam ter recebido orientações de higiene vocal, e os do grupo 2 (SASSEP) já teriam recebido essas orientações, anteriormente por uma profissional fonoaudióloga da instituição.

No grupo 1 (PIBR), a idade mínima encontrada foi de 53 anos e máximo a de 99, numa média de 64 anos. No grupo 2 (SASSEP) a idade mínima encontrada foi de 66 anos e máxima de 84 anos, numa média de 74 anos.

A pesquisa foi realizada por meio da aplicação de questionário (Figura 1) com questões do tipo fecha$\mathrm{da}$, previamente elaboradas com base em textos das seguintes literaturas: Higiene vocal - cuidando da voz (Behlau, Pontes 1999) e Intervenção fonoaudiológica na terceira idade (Russo -1999).

Este estudo foi aprovado pelo Comitê de Ética da Universidade Federal de Pernambuco conforme o Protocolo de Pesquisa n066/2004-CEP/CCS, tendo todos os indivíduos estudados assinado o Termo de Consentimento Livre e Esclarecido.

Para análise dos resultados, foram utilizadas técnicas de estatística descritiva, por meio da distribuição de freqüência absoluta e relativa, bem como a apresentação tabular.

\section{RESULTADOS}

De acordo com as perguntas do questionário, os pesquisados foram, a princípio, indagados quanto à ocupação. O grupo 1 (sem orientação) era compos- 
to, em sua maioria de nove domésticas $(42,9 \%)$, três aposentados $(14,3 \%)$, três professores $(14,3 \%)$, três advogados $(9,5 \%)$, um comerciante $(4,75 \%)$, um pastor $(4,75 \%)$, um técnico de laboratório $(4,75 \%)$ e uma costureira $(4,75 \%)$. No grupo 2 (com orientação), também foram encontradas sete domésticas $(33,3 \%)$, seis aposentados $(28,5 \%)$, três costureira $(14,2 \%)$, além de uma enfermeira (4\%), uma socióloga (4\%), uma secretária (4\%), uma confeiteira (4\%), um pensionista (4\%), uma tecelã (4\%). Houve um sujeito do grupo 2 que não referiu a sua ocupação.

Com relação à presença de sintomas de alterações vocais observa-se na Tabela 1 , o relato de cansaço na voz e dor na garganta, no grupo 1, a freqüência foi equivalente 11 (50\%). Já no grupo 2, esses sintomas, tem freqüência menor, 10 (40\%) e 11 (48\%), respectivamente. Quanto à presença de sensação de corpo estranho, o grupo 1 possui uma freqüência significativa de 14 (67\%), diferente do resultado obtido no grupo 2 que foi de 9 (39\%). Referente à rouquidão, o relato desse sintoma é menor em ambos os grupos, no entanto, no grupo 1, que não recebeu orientação vocal, a freqüência é maior 10 (45\%) do que no grupo 2, 8 (35\%).

Quanto às formas de prevenção dos distúrbios da voz (Tabela 2), a maioria 15 (65\%) do grupo 1 (sem orientação), não referem cuidados vocais. Dos que realizam alguma prevenção dos distúrbios da voz, 5 $(26 \%)$ referiram uso de receitas caseiras, 1 (4,5\%) citaram utilizar medicação e 1 (4,5\%), de spray e pastilhas. Já no grupo 2 (com orientação), que recebeu orientação vocal, a maioria referiu realização de prevenção da voz, como: uso de medicação, 3 $(13,7 \%)$; receitas caseiras $1(6,3 \%)$; spray e pastiIhas, 1 (6,3\%); receitas caseiras e medicação, 1 $(6,3 \%)$; receitas caseiras, medicação e spray e pastilhas, 1 (6,3\%); receitas caseiras, medicação, spray e pastilhas e treinamento vocal $1(6,3 \%)$ e treina- mento vocal $3(13,7 \%)$, composto pelas técnicas de aquecimento e desaquecimento passado em orientação vocal.

Concernente, aos hábitos vocais, o grupo 2 (com orientação), possui menor freqüência de realização de hábitos inadequados quando comparando ao grupo 1 (sem orientação), porém os hábitos encontrados no grupo 1 (sem orientação) foram: pigarrear 10 $(45,45 \%)$, tossir $6(27,3 \%)$, seguido do hábito de falar muito $2(9,06 \%)$ e gritar $1(4,54 \%)$. No grupo 2 (com orientação), apesar da menor presença de hábitos inadequados ao comparar com o grupo 1, constatou-se que alguns idosos não relataram possuir apenas um hábito, mas hábitos associados, como: tossir e pigarrear $4(17,6 \%)$, gritar e falar muito 1 $(4,4 \%)$, gritar e pigarrear $1(4,4 \%)$, gritar, tossir e pigarrear 1 (4,4\%) (Tabela 3).

No grupo 1 (sem orientação), 20 (90,9\%) referiram não possuir patologias vocais no momento da aplicação do questionário, apenas $2(9,1 \%)$ relataram alterações como: edema de Reinke e hiperemia. No grupo 2, apenas $4(17,4 \%)$ disseram que possuíam alterações, dentre elas: nódulo e hiperemia.

Quanto a presença de problemas alérgicos, o grupo 1 (sem orientação), apresentou uma freqüência de $12(54,5 \%)$ e o grupo 2 (com orientação), de 10 $(45,4 \%)$. No grupo 1 (sem orientação), 6 (27,3\%) referiram que não tem problemas alérgicos e 4 (18,2\%) não souberam referir sobre o assunto. Já no grupo 2 (com orientação), 6 (27,3 \%) não possuem e 6 $(27,3 \%)$ não sabem referir.

Em relação à hidratação, no grupo 1 (sem orientação), que não recebeu nenhuma orientação sobre saúde vocal, $8(36,4 \%)$ relatam que bebem bastante líquido por dia e $14(63,6 \%)$ não têm esse hábito. Já no grupo 2 (com orientação), 12 52,2\% disseram que bebem bastante líquido e 11 (47,8\%) que não bebem bastante líquido.

Tabela 1 - Distribuição quanto à presença dos sintomas entre os grupos 1 (sem orientação) e 2 (com orientação), no período de outubro a novembro de 2005

\begin{tabular}{ccccc}
\hline GRUPO & \multicolumn{2}{c}{ GRUPO 1} & GRUPO 2 \\
\hline RESPOSTAS & Sim & Não & Sim & Não \\
Cansaço na voz & (11) $50 \%$ & (11) $50 \%$ & (10) $40 \%$ & (13) $60 \%$ \\
Dor na garganta & (11) $50 \%$ & (11) $50 \%$ & (11) $48 \%$ & (12) $52 \%$ \\
Sensação de corpo & & & & \\
estranho & (14) $67 \%$ & ( 8 ) $33 \%$ & (9) $39 \%$ & (14) $61 \%$ \\
Rouquidão & (10) $45 \%$ & (12) $55 \%$ & ( 8 ) $35 \%$ & (15) $65 \%$ \\
\hline
\end{tabular}


Tabela 2 - Distribuição quanto as formas de prevenção entre os grupos 1 (sem orientação) e 2 (com orientação), no período de outubro a novembro de 2005

\begin{tabular}{ccc}
\hline RESPOSTAS & GRUPO1 & GRUPO 2 \\
\hline Nenhuma & $(15) 65 \%$ & $(12) 41,1 \%$ \\
Medicação & ( 5 ) $23,8 \%$ & ( 3 ) $13,7 \%$ \\
Receitas caseiras & (1) $4,5 \%$ & (1) $6,3 \%$ \\
Spray e pastilhas & (1) $4,5 \%$ & (1) $6,3 \%$ \\
Receitas caseiras e medicação & - & (1) $6,3 \%$ \\
Receitas caseiras, medicação e & - & (1) $6,3 \%$ \\
spray/pastilhas & - & (1) $6,3 \%$ \\
Receitas caseiras, medicação, \\
Spray/pastilhas e treinamento vocal \\
Treinamento vocal
\end{tabular}

Tabela 3 - Distribuição quanto aos hábitos vocais entre os grupos 1 (sem orientação) e 2 ( com orientação), no período de outubro a novembro de 2005

\begin{tabular}{|c|c|c|}
\hline RESPOSTAS & GRUPO1 & GRUPO 2 \\
\hline Nenhum & ( 3 ) $13,65 \%$ & ( 9 ) $38,4 \%$ \\
\hline Gritar & ( 1 ) $4,54 \%$ & ( 1 ) $4,4 \%$ \\
\hline Tossir & ( 6 ) $27,3 \%$ & ( 1 ) $4,4 \%$ \\
\hline Pigarrear & (10) $45,45 \%$ & ( 2 ) $8,8 \%$ \\
\hline Falar muito & ( 2 ) $9,06 \%$ & ( 3 ) $13,2 \%$ \\
\hline Gritar e falar muito & - & (1) $4,4 \%$ \\
\hline Tossir e pigarrear & - & ( 4$) 17,6 \%$ \\
\hline Gritar e pigarrear & - & ( 1 ) $4,4 \%$ \\
\hline \multicolumn{3}{|l|}{ Gritar, tossir e } \\
\hline pigarrear & - & (1) $4,4 \%$ \\
\hline Total & (22) $100 \%$ & (23) $100 \%$ \\
\hline
\end{tabular}




\section{QUESTIONARIO}

1)Idade: $\quad$ 2)Profissão:

3) Você costuma apresentar cansaço na sua voz? 3.1( ) sim 3.2( ) não

4) Você costuma apresentar dor na garganta? 4.1( ) sim 4.2( ) não

5) Você costuma apresentar sensação de corpo estranho? 5.1( ) sim 5.2( ) não

6) Você costuma apresentar rouquidão? 6.1( ) sim 6.2( ) não

7) Você realiza alguma prevenção para sua voz?

7.1( ) não 7.2( ) medicação 7.3 ( ) receitas caseiras $7.4($ ) sprays e pastilhas 7.5 ( ) treinamento vocal $7.6($ ) outros:

8) Quais os hábitos vocais mais freqüentes que você costuma realizar?

8.1( ) nenhum 8.2( ) gritar 8.3( ) tossir 8.4( ) pigarrear 8.5( ) falar demasiadamente, muito 8.6 Outros:

9) Teve ou tem alguma doença diagnosticada nas cordas vocais? 9.1 ( ) não 9.2 ( ) sim. Em caso de sim, qual?

9.2.1( ) nódulo 9.2.2( )pólipo 9.2.3( ) granuloma 9.2.4( ) edema de Reinke 9.2.5

Outros:

10) Apresenta problema alérgico? 10.1 ( ) sim 10.2 ( ) não 10.3 ( ) não sabe

11) Bebe bastante líquido por dia? 11.1( ) sim 11.2 ( ) não

12) Já participou de alguma orientação sobre prevenção e/ou técnicas vocais?

12.1 ( ) $\operatorname{sim} 12.2$ ( ) não

Figura 1 - Questionário aplicado no Grupo 1 (PIBR) e no Grupo 2 (SASSEP)

\section{DISCUSSÃO}

Quanto à presença de sintomas (cansaço ao falar, dor na garganta, sensação de bolo na garganta e rouquidão), os sujeitos do grupo que já foi orientado possuem uma freqüência de sintomas menor, quando comparado ao grupo 1 ( que não recebeu orientação), constatando que as orientações fonoaudiológicas podem ter beneficiado o grupo que as recebeu, apesar dos sintomas de cansaço ao falar, ou seja, redução da capacidade respiratória vital e a rouquidão serem características vocais de idosos ${ }^{10}$.

Vale ressaltar que atrofia e fenda glótica são mudanças laríngeas presentes na senescência ${ }^{11}$. Ou seja, a fenda sugere mudanças na capacidade respiratória, evidenciando este sintoma de cansaço ao falar, que junto à atrofia dão origem à rouquidão. Além da alteração glótica é importante destacar que com o avanço da idade ocorre endurecimento do tórax e enfraquecimento dos músculos respiratórios, favorecendo ainda mais a redução da capacidade respiratória ${ }^{10,12}$.

Já o sintoma de sensação de bolo na garganta pode ser uma das características do distúrbio do refluxo gastroesofágico, contudo não se pode afirmar que os pesquisados tenham o distúrbio, mas precisam ser encaminhados a um gastroenterologista. $\mathrm{O}$ refluxo irrita a mucosa laríngea, podendo levar a lesões, como o granuloma e há teorias que atribuem o desenvolvimento do câncer de laringe a um processo inflamatório irritativo devido ao refluxo gastroesofágico 9 . O refluxo é favorecido por substâncias como alimentos gordurosos e condimentados, bebidas gasosas, entre outros ${ }^{9}$. 
Quanto à dor na garganta, pode ser conseqüência da hiperemia ou abuso vocal ${ }^{9}$.

Verifica-se que apesar de um grupo ter recebido orientações sobre saúde vocal, não impediu o uso de receitas caseiras, associados ao uso de spray, pastilhas e medicação. Observa-se também uma porcentagem de indivíduos que apenas fazem treinamento vocal como forma de prevenção, mostrando alguma mudança de hábito neste grupo.

Deve-se ter cuidado com o hábito da automedicação, uma vez que há medicamentos que causam alteração no trato vocal, além do uso de receitas caseiras, que ainda tem ação desconhecida para as pregas vocais, podendo, em determinados casos, apresentar efeitos secundários ${ }^{8}$.

O uso de spray e pastilhas, sem prescrição médica, pode apresentar efeitos anestésicos, mascarando a dor na garganta ou esforço vocal, podendo ser irritantes, aumentar a quantidade e a viscosidade da saliva ${ }^{8}$.

O uso do gengibre, apesar de seu efeito cicatrizante, pode irritar a mucosa da laringe, desencadeando tosse intensa, além de ser uma das substâncias, que modificam a sensibilidade e propriocepção oral e faríngea ${ }^{13}$. Esse efeito de modificação da sensibilidade também ocorre no uso de própolis, vinagre, canela, entre outras receitas caseiras, utilizadas ${ }^{13}$. Observam-se a presença desses métodos paliativos como uso de medicação, receitas caseiras, spray e pastilhas nos dois grupos.

Referente aos hábitos vocais, no grupo 1 , o hábito de pigarrear foi o mais relatado. O grupo 2 (com orientação) apresentou menor freqüência de hábitos vocais, tendo alguns indivíduos, apresentado hábitos associados, sendo a associação mais insidiosa o ato de tossir e pigarrear. $\mathrm{O}$ ato de pigarrear pode estar relacionado à promoção de sensação de eliminação de corpo estranho da laringe, aliviando o sintoma de pressão na garganta, com eventual melhora da voz ${ }^{8,9}$. Tal gesto, porém, é uma agressão para as pregas vocais, piorando a condição laríngea, porque cria uma região de atrito na glote. Já a tosse é um gesto extremamente agressivo para a delicada mucosa da laringe, pois as pregas vocais batem uma contra a outra ${ }^{8,9}$. Os dois procedimentos acima citados (pigarro e tosse) agridem as pregas vocais e como reação ao atrito ocorre aumento de muco para se proteger do impacto.

No grupo 2, há uma pequena freqüência quanto ao ato de falar muito, a qual sugere uma sobrecarga vocal principalmente, numa fala rápida, sendo importante o cuidado com esse hábito ${ }^{9}$. O grito também é um abuso vocal e agride as pregas vocais. No momento do grito, o ar pode chegar a $80 \mathrm{Km} / \mathrm{h}$ na região glótica, e as pregas vocais se golpeiam, aumentando o tônus da musculatura cervical e a sobrecarga no aparelho fonador ${ }^{8}$.
Observa-se a presença de patologias em ambos grupos, tendo o relato de hiperemia nos dois grupos da terceira idade. Outras patologias foram referidas, como nódulo e edema de Reinke, revelando com isso a presença de abusos vocais nesses sujeitos, já citados anteriormente.

Em um estudo com idosos, numa média de idade de 75 anos, de ambos os sexos, utilizando avaliação laringoscópica indireta e avaliação da qualidade vocal, o aspecto morfológico evidente, era o edema de prega vocal, com grande freqüência, tanto em mulheres, com em homens, além de atrofia de prega vocal, sendo observado a fenda glótica, com maior freqüência nos homens ${ }^{12}$.

Há estudos que atribuem à presença do edema de prega vocal nas mulheres às mudanças endócrinas após a menopausa ${ }^{12}$.

Sabe-se que as alergias são fatores propícios para o desenvolvimento de problemas na voz, e a presença da mesma foi relatada nos dois grupo, sendo maior nos sujeitos do grupo 1. Quando manifestadas nas vias respiratórias como bronquite, asma, rinite e laringite, observa-se um edema nas mucosas respiratórias, dificultando a vibração das pregas vocais ${ }^{6}$. Há uma tendência de surgir edema nas mucosas respiratórias, devido a alergia, dificultando a vibração das pregas vocais ${ }^{8,9}$. Como foi relatado a presença de hiperemia pelos grupos, é sempre recomendável o aumento da hidratação no período de crises alérgicas ${ }^{9}$.

Percebe-se que o grupo que já recebeu orientação vocal (SASSEP) tem o hábito de ingerir bastante líquido por dia, podendo ser decorrente do conhecimento passado quanto à importância da hidratação. Aágua é um componente vital para todas as funções de nosso corpo e a produção vocal também depende dela. O ideal seria beber dois litros de água ao dia, ou seja, oito a dez copos, para garantir a reposição das perdas pela urina e a transpiração, sendo essa ingestão fora dos horários das refeições ${ }^{8,9}$. Um corpo com uma hidratação adequada permite uma boa ingestão de água é um fator importante, que pode prevenir ou retardar o aparecimento de fadiga vocal, caracterizada por vários sintomas, como cansaço, dor, ardor, tensão na musculatura laríngea, região do pescoço, rouquidão progressiva, sem lesões na prega vocal, alterações na qualidade vocal, esforço fonatório, entre outros ${ }^{13}$.

Percebe-se, assim a importância da promoção de palestras sobre saúde vocal aos idosos, pois, mesmo com pouca adesão às modificações de hábitos, ocorreram mudanças. Apesar do grupo 2 ter recebido orientações de saúde vocal no ano anterior a esta pesquisa, sugere-se a necessidade de realizações periódicas de palestra com os mesmos e que seja dado início a orientações vocais no grupo que não tem esse conhecimento, afim de se minimizar os hábitos inadequados, favorecendo uma melhor voz. 


\section{CONCLUSÃO}

Verifica-se que os sintomas de cansaço ao falar, dor de garganta, sensação de bolo na garganta e rouquidão, é mais presente no grupo que não recebeu orientações quanto à saúde vocal e que não adota for- mas de prevenção (Grupo 1 - sem orientação), diferente do grupo 2 (com orientação), que apesar de realizarem formas errôneas para prevenção de alterações da voz, incluem o treinamento vocal. Contudo, é positivo observar uma porcentagem de indivíduos que realizam apenas as técnicas vocais passadas na orientação vocal.

\begin{abstract}
Purpose: to compare the differences as for the presence of inadequate habits, forms of prevention and vocal symptoms, more frequent, in two groups of the third age. Methods: a questionnaire was applied with questions of the closed type, previously elaborated in the 45 aged of both genders, being that only one group received vocal orientation during the previous year the research by a speech therapist professional. It is a study of the descriptive, observational, transversal. Results: of accordance with the results, group 2 that received orientation vocal, has minor frequency of inadequate habits when compared with group 1. As for the forms of prevention of riots in the voice, the majority of group 1, does not take any care. In group 2 , it is already evidenced, among others prevention forms, the reference regarding accomplishment of vocal training. With regard to the presence of symptoms, group 1 showed greater frequency as for the fatigue when speaking $(50 \%)$, pain in throat $(50 \%)$, sensation of strange body $(67 \%)$, than group 2. Conclusion: we note that thee has been differences as for inadequate habits, forms of prevention and symptoms in the two groups, being that group 2 (that received orientation as for to the cares related to voice) has minor indices as for to the inadequate habits and vocal symptoms, that is, in accordance with the results, orientation on vocal health in groups of third age is efficient.
\end{abstract}

KEYWORDS: Aged; Speech; Aging Heath; Language and Hearing Sciences; Habits

\section{REFERÊNCIAS}

1. Grinover P. Poder da terceira idade [periódico online]. Portal da família 2004. Disponível em: URL: http://www.portaldafamilia.org/artigos/artigo132.shtml. 2. Canineu PR, Canineu RFB, Canineu PRB, Silva $M C$. Terapia multidisciplinar: uma proposta de tratamento global do idoso [periódico online]. Mundo Saúde 2005; 29(4) 4):662-665.

3. Hirano M, Kurita S, Sakaguchi S. Ageing of the vibratory tissue of human vocal folds. Acta Otolaryngol.

\section{RECEBIDO EM: 22/09/2006}

ACEITO EM: 12/05/2007

Endereço para correspondência:

Rua Manoel Nascimento Torres, quadra k, Lote01, $\mathrm{n}^{\circ} 30$

Goiana - PE

CEP: $55900-000$

Tel/fax: (81) 36260713 / 88174744

E-mail: elissoares@hotmail.com
1989; 107(5-6):428-33.

4. Biase NG, Cervantes O, Márcio A. A voz no idoso [periódico online]. Acta AWHO. 1998;17(2): 70-2.

5. Prado SD, Sayd JD. A pesquisa sobre envelhecimento humano no Brasil: grupos e linhas de pesquisa [periódico online]. Ciência e saúde coletiva 2004; 9(1): 57-67.

6. Behlau M. Voz: o livro do especialista. v. 1. Rio de Janeiro: Revinter; 2001.348 p.

7. Morrison MD, Hickman GP. Voice disorders in the elderly. J Otolaryngol. 1986; 71: 231-4.

8. Pinho SMR. Fundamentos em fonoaudiologia: tratando os distúrbios da voz. Rio de Janeiro: Afiliada; 1998. $125 \mathrm{p}$.

9. Behlau M, Pontes P. Higiene vocal: cuidando da voz. Rio de Janeiro: Revinter; 1999. 61 p.

10. Morsomme D, Jamart J, Boucquey D, Remacle M. Presbyphonia: voice differences between the sexes in the elderly: comparison by maximum phonation time, phonation quotient an spectral analysis. Log Phon Vocol. 1997; 22:9-14.

11. Honjo I, Isshiki N. Laryngoscopic and voice characteristics of aged persons. Arch Otolaryngol. 1980; 106(3):149-50.

12. Dhar S, Shastri SR, Lenora RA. Aging and the respiratory system. Med Clin North Am. 1976; 60(6):1121-39.

13. Kubota ML. Considerações sobre a hidratação das pregas vocais [monografia]. São Paulo (SP): CEFAC - Saúde e Educação;1997. 